\title{
Türkiye'de Bağımsız Denetim Şirketlerinde Kadın Denetçilerin Unvanlarına Göre Yönetime Katılma Durumlarının İncelenmesi*
}

\author{
Sedat COŞKUN**
}

\section{ÖZET}

Bu çalışmada temel amaç Türkiye'de kadın denetçilerin bă̆ımsız denetim firmalarının yönetimlerinde hangi unvanlar ile erkek denetçilere oranla yer alabildiklerini ortaya koymaktır. Bu çerçevede Türkiye'de faaliyette bulunan 4 büyük denetim firması dahil olmak üzere 8 büyük denetim firmasının 2015-2019 yıllarl arasındaki şeffaflık raporlarındaki verileri incelenmiştir. Çalışma verileri betimleyici istatiksel yöntem uygulanmak suretiyle frekans ve yüzde değerleri üzerinden analiz edilmiştir. Çalışmanın 5 yıllık ortalama değerleri kadın denetçilerin sorumlu denetçi olarak \%32, ortak denetçi unvanı ile \%27, kilit yönetici unvanı ile $\% 24$, yönetim kurulu üyesi olarak ise \%21 oranında denetim şirketlerinde görev alabildiklerini göstermiştir. Bununla birlikte çalışma verileri kadın denetçilerin \%12 oranında yönetim kurulu başkanlığı görevini yerine getirdiğini ve sorumlu ortak baş denetçi olarak ise \%7,94 oranında yönetimde yer aldıklarını ortaya koymuştur. Araştırmanın nihai sonuçları Türkiye'de bağımsız denetim şirketlerinde kadın denetçilerin yönetimdeki varlıklarının düşük düzeyde olduğunu ve erkek denetçilerin yönetimlere egemen olduğunu göstermiştir.

Anahtar Kelimeler: Kadın Denetçiler, Bă̆ımsız Denetim, Yönetim.

JEL Sinıflandırması: M40, M42.

\begin{abstract}
Review of Women Auditors' Participating Case In The Management Of Independent Audit Companies In Turkey By Title

\section{ABSTRACT}

The main objective of this work is by which titles women auditors can take place in the management of the independent audit firms in Turkey compared to men auditors. In this context, it was examined that the data in the transparency reports of 8 big auditor firms operating in Turkey between the years 2015 and 2019 including 4 big audit firms. The study data were analyzed over frequency and percentage values by applying the descriptive statistical method. The 5-year average values of the study prove that women auditors can work in the audit companies at $32 \%$ as responsible auditors, $27 \%$ as partner auditors, $24 \%$ as key managers, and $21 \%$ as members of the managing board. At the same time, the study data revealed that the female auditors served as the chairman of the managing board at a rate of $12 \%$ and that they took part in the management at a rate of $7.94 \%$ as the responsible partner chief auditor. The final results of the study proved that the presence of the management of female auditors in the independent audit companies are at low levels and that male auditors are dominant.
\end{abstract}

Keywords: Women Auditors, Independent Audit, Management.

Jel Classification: M40, M42.

* Bu makale, 23-25 Nisan 2021 tarihleri arasında gerçekleştirilen VI. Uluslararası Muhasebe ve Finans Sempozyumunda bildiri olarak sunulmuştur.

Makale Gönderim Tarihi: 17.05.2021, Makale Kabul Tarihi: 31.05.2021, Makale Türü: Nicel Analiz

** Dr. Öğr. Üyesi, Manisa Celal Bayar Üniversitesi, Salihli İktisadi ve İdari Bilimler Fakültesi, sedat.coskun@cbu.edu.tr, ORCID: 0000-0003-1364-6516. 


\section{GİRIŞ}

Türkiye coğrafyasında Osmanlı devleti döneminde 18. yüzyılın sonlarına doğru başlatılan batılılaşma hareketleri ve devamında gelen II. Meşrutiyetin ilanı ile kadının eğitim hayatında varlığının artırılması amaçlanmıştır. Bu durum Türk kadınını sosyal ve ekonomik hayat içerisinde daha görünür hale getirmiştir (Özkiraz ve Arslanel, 2011:2). Cumhuriyetin ilanı ile kadının özellikle çalışma hayatındaki varlığı günümüze kadar artarak gelmiştir. Buna karşın eskiye oranla kadınların çalışma hayatı içerisinde varlığı artmış olsa da yayınlanan istatiksel veriler Türkiye'de kadın çalışanların iş hayatında yeterli oranda var olamadıklarını ortaya koymaktadır.

Türkiye İstatistik Kurumu'nun açıklamış olduğu verilere göre kadınların iş gücüne katılma oranı 2017 yılında \%33, 2018 yılında ise \%34'tür (www.data.tuik.gov.tr, 2021). Dünya ekonomik formunun 2020 yılında yayınlamış olduğu küresel cinsiyet eşitsizliği raporuna göre toplam 153 ülke içerisinde Türkiye 130'uncu sıradadır. Rapordaki bölgesel (Ortadoğu ve kuzey Afrika) sıralamaya göre 19 ülke içerisinde Türkiye dördüncü, İsrail birinci sıradadır. Yemen ise en son sirada yer almaktadır (www3.weforum.org, 2021). Uluslararası Çalışma Örgütü (ILO) verilerine göre ise Türkiye'deki bütün sektörlerde kadın çalışanların yönetim pozisyonlarında yer alma oranları 2015 yılında $\% 13,2,2016$ ' da $\% 15,1$, 2017 'de $\% 15,2018$ 'de \%14,8 ve 2019 yılında ise \%16,2 olarak raporlanmıştır. Son beş yıllık ortalamaya bakıldığında kadın çalışanların yönetimdeki oranları yaklaşık \%15'tir (www.ilo.org, 2021). İlgili küresel kuruluşlar ve TÜIKK tarafından açıklanan bu veriler Türkiye gibi genç dinamik çalışabilir kadın nüfusa sahip bir ülke için kadın çalışanların çalışma hayatı içerisindeki varlıklarının ve yönetime katılma oranlarının düşük düzeyde olduğunu göstermektedir.

Günümüzde gelişmiş ülkeler başta olmak üzere birçok ülkede kadın çalışanların çalışma hayatı içerisindeki varlıkları geçmişe oranla yapılan birtakım pozitif uygulamalarla artırılmaya çalışılmaktadır. Örneğin kurumsal yapılarda oluşturulan kurullarda Norveç özelinde yapılan düzenlemelere göre en az yüzde kırk oranında kadın yöneticiler bulundurulması zorunlu tutulmaktadır. Almanya'da benzer uygulamalar mevcuttur. Almanya'da şirketlerin denetim kurullarında yüzde otuz oranında kadın çalışanın olması şart koşulmaktadır. İsveç’te kurumsal yapılarda oluşturulan kurullarda yüzde yirmi beş oranında kadın yöneticilere yer verilmesi için yasal mevzuat önerilmiştir. İspanya'da kadın temsil oranının yüzde kırklara çıkarılması tartışılmaktadır (Burke ve Vinnicombe, 2008:3). Diğer yandan, kadının iş hayatında erkekler gibi var olabilmesi doğuştan kazanılmış bir hak olması gerekirken yine erkek egemen yöneticiler tarafından bir takım "pozitif ayrımcılıklarla" artırılmaya çalışılmaktadır. Bu durum konunun esasen daha derin eğitim, ekonomik, sosyal ve kültürel boyutlarının olduğunu ortaya koymaktadır.

Kadının çalışma hayatı içerisinde var olabilmesi için en önemli etkilerden bir tanesi şüphesiz eğitimdir. Fransız sosyolog Pierre Bourdieu bireylerin eğitiminin sadece okul hayatında gerçekleşmediğini aile içerisinden gelen bazı özelliklerin de eğitim yaşamına büyük ölçüde katkı sağladığını ifade etmektedir. Bu çerçevede Klynveld Peat Marwick Goerdeler (KPMG) denetim firması tarafından Türkiye özelinde yapılan ve 2017 yayınlanan "kilidi kırmak" isimli çalışmada yönetim pozisyonlarında yer alan kadın çalışanların aile bireylerinin büyük bir çoğunluğunun pilot, subay, öğretmen, mühendis gibi eğitimli bireylerden oluştuğu belirlenmiştir (https://home.kpmg/tr, 2017). Bu sonuç kadının çalışma hayatında erkeklere 
oranla katılım sağlanmasında en büyük itici gücün okul ve bilinçli bir aile içinde sürdürülen eğitim hayatının etkili olduğunu göstermektedir.

Literatürde yapılan çalışmalar kadın çalışanların iş yaşamında erkelere oranla birçok yönden daha başarılı olduklarını ortaya koymaktadır. Kadın çalışanların erkek çalışanlara oranla kurumsal olarak karar almada firsatçı davranışlara karşı daha mesafeli durdukları (Krishnan ve Parsons, 2008:66) ve kadın çalışanların aynı zamanda etik ilkelere daha fazla uyan kararlar aldıkları ifade edilmektedir. Bununla birlikte kadın çalışanların maddi kazanç sağlamak için erkeklere oranla etik olmayan davranışlarda bulunma olasılıklarının daha düşük olduğu açıklanmaktadır (Arioglu, 2020: 928). Aynı zamanda kadın çalışanların görev aldıkları kurullarda erkeklere kıyasla görevlerini daha titiz ve bağımsız bir şekilde yerine getirebildikleri de ifade edilmektedir ( $\mathrm{Li}$ ve $\mathrm{Li}$, 2020:3). Kadın çalışanların şirketlerin yönetimlerinde daha fazla yer almalarının genel itibari ile firmaların karlılıklarını olumlu etkilediği ve daha yüksek oranda hisse senedi getirisi sağladığı da savunulmaktadır (Krishnan ve Parssons, 2008:66). Literatürde şirket yönetimlerinde üst düzey seviyelerde kadın çalışan sayısı fazla olduğunda firmalarının bilanço öz kaynaklarında ve gelirlerinde artış olduğu da açıklanmaktadır (Baskan, 2018:200). Bu çalışmada bağımsız denetim şirketlerinde kadın denetçilerin hangi unvanlarla yönetime ne derecede katılabildikleri araştırılmıştır. Bu çerçevede Türkiye'de bağımsız denetim sektöründe faaliyette bulunan denetim şirketleri üzerine bir inceleme yapılmıştır. Araştırmada bağımsız denetim şirketleri seçilirken denetim gelirleri toplamları ve denetim hizmeti verdikleri Kamu Yararını İlgilendiren Kuruluş sayıları göz önüne alınmıştır. Yapılan bu sınıflandırma kapsamında araştırmada aralarında dört büyük (big four) denetim şirketlerinin bulunduğu 8 büyük denetim firmasının 2015-2019 yıllarına ait şeffaflık raporları kullanılmıştır. Çalışmada öncelikle araştırma konusuyla ilgili literatür incelenmiştir. Ardından çalışmanın amacı, kapsamı ve yöntemi ele alınmıştır. Daha sonra çalışmanın bulgularına ve sonucuna yer verilmiştir.

\section{LITERATÜR ARAŞTIRMASI}

Literatürde bağımsız denetimin değerlendirmesinde girdi ve çıktı temelli olmak üzere iki temel değişken bulunduğu açıklanmaktadır. Çıktı temelli değişkenler; maddi yanlış içeren ifadeleri, denetçi iletişimini, finansal raporlama kalitesini ve algı temelli ölçüleri ifade etmektedir. Girdi temelli değişkenler ise iki grupta toplanmaktadır. Denetçi karakteristik özellikleri ile denetçi-müşteri sözleşme özellikleridir. Denetçi karakteristik özellikleri denetçinin büyüklüğünü örneğin dört büyük denetim şirketleri içerisinde yer alma gibi ve belirli bir sektörde uzmanlaşmayı ifade etmektedir. Denetçi müşteri sözleşme özellikleri ise denetim faaliyetinin bir karşıllğ 1 olan denetim ücreti ile ilgilidir (DeFond ve Zhang, 2014:276-289). DeFond ve Francis (2005), Ittonen ve Peni (2012) tarafindan denetim ücretleri sözleşmeleri üzerinde denetçilerin bireysel özelliklerinin de etkili olabileceği ileri sürülmektedir. Buradan hareketle denetim gelirleri üzerinde cinsiyet faktörünün de bir etki faktörü olabileceği (Abed ve Al-badainah, 2013: 127) ve diğer bir anlatımla denetçinin taşımış olduğu kişisel özelliklerin örneğin; risk algısı, liderlik, karar vermedeki davranışların denetim gelirlerinin sağlandığı müşteri ile yapılan sözleşmedeki ücreti etkilediğidir (Ittonen ve Peni, 2012:2). Bu bağlamda kadın denetçilerin risklere karşı daha duyarlı ve daha fazla algılarının açık oldukları, bu sayede erkek denetçilere oranla daha az düzeyde riskli davranış gösterdikleri de literatürde ifade edilmektedir (Abdelfattah vd., 2020:13). Bununla birlikte denetim komitesi başkanlık görevlerinin kadın yöneticiler tarafından yerine getirilen şirketlerde daha düşük oranda kurumsal mali düzensizliklerle karşılaşıldığı (Li ve Li, 2020:3) 
ve aynı zamanda kadın denetçilerin maddi yanlışlıkları daha fazla tespit edebildikleri görüşü dile getirilmektedir (Breesch ve Branson, 2009:85). Diğer yandan girdi temelli özellikler aynı zamanda mali tablo raporlama sürecini ve denetim kalitesini etkileyen değişkenler olarak da kabul edilmektedir (Erdoğan ve Kutay, 2016: 108). Bununla birlikte literatürde denetim kalitesinin finansal raporların güvenilirliğini ve kalitesini artırdığı savunulmaktadır (DeFond ve Zhang, 2014:276). Watts ve Zimmerman (1981)'a göre ise kaliteli bir denetim faaliyetinin işletme sahipleri ile mali tablo bilgi kullanıcıları arasındaki "asimetrik bilgiyi" azaltabildiği de ifade edilmektedir (Yanık ve Karataş, 2017:2). Literatürde yapılan çalışmalarda araştırmacıların sıklıkla bağımsız denetim firmalarında kadın çalışanların sorumlu denetçi ve diğer unvanlarla görev alma durumları ile denetim ücreti gelirleri, denetim kalitesi arasındaki ilişkiyi inceledikleri görülmüştür. Bu çerçevede; Ittonen vd. (2013) Hardies vd. (2015), Hardies vd. (2018), Li vd. (2017), Burke vd. (2019), Lee vd. (2019), yapmış oldukları çalışmalarda kadın denetçiler ile denetim kalitesi ve denetim ücretleri arasında pozitif yönde ilişki olduğunu tespit etmişlerdir (Hao vd., 2021:3). Bununla birlikte literatürde içeriği farklı olan çalışmalarda aynı zamanda unvanlarına göre kadın denetçilerin bağımsız denetim firmalarındaki dağılımları da incelenmiștir. Örneğin Türkiye özelinde 2017 yılında yapılan çalışmada KAYİK denetimi yapan 84 bağımsız denetim şirketi içerisinde 472 sorumlu denetçiden 48 tanesinin kadın denetçi olduğu tespit edilmiştir (Bozcuk, 2018: 886). Türkiye özelinde 2017 yılında yapılmış başka bir araştırmada ise İstanbul, Ankara ve İzmir illerinde bulunan bağımsız denetim firmalarında sorumlu ortak baş denetçi, kıdemli denetçi, baş denetçi, denetçi, denetçi yardımcısı gibi unvanlarla çalışan toplam 344 denetçinin 128 tanesinin kadın denetçilerden oluştuğu belirlenmiştir (Hatunoğlu ve Koca, 2020: 625-630). Sarıçiçek ve Aytekin (2020) tarafından yapılmış farklı bir çalışmada ise 2018 yılı verilerine göre 274 örneklem içerisinde kadın denetçilerin oranın \%22,3 olduğu tespit edilmiştir. Almanya özelinde 2014-2018 yılları arasında dört büyük denetim firması üzerine yapılan araştırmada ise 397 denetçi içerisinde kadın denetçilerin ortalama oranın \%21 olduğu belirlenmiştir. Aynı araştırmada kıdemli ortak 63 denetçi içerisinde kadın denetçilerinin ortalama oranın \%11 olduğu tespit edilmiştir (Downar, Ernstberger ve Koch, 2020: 9). Avrupa özelinde daha önce yapılmış çalışmalarda kadın denetçilerin denetim şirketlerindeki varlıklarında benzer sonuçlar olduğunu göstermektedir. Bu bağlamda Finlandiya, İsveç ve Danimarka özelinde yapılan cinsiyet ve denetim gelirlerinin etkileşimine ilişkin çalışmada kadın denetçilerin 2005 yılındaki üç ülkedeki toplam oranı \%12,91, erkek denetçilerin oranı \%87,09 olarak belirlenmiştir. 2006 yılında ise kadın denetçilerin oranı 12,83 ve erkek denetçilerin oranı \%87,17 olarak tespit edilmiştir (Ittonen ve Peni, 2012:6). Dambrin ve Lambert (2008) tarafından Fransa özelinde yapılan başka bir araştırmada ise kadın denetçilerin düşük düzeyde yönetimde yer alabildikleri ifade edilmiştir. ABD'de yapılan çalışmalarda da benzer sonuçlara ulaşıldığ 1 görülmektedir. Bu çerçevede Hairston, Wu ve $\mathrm{Yu}$, (2019) tarafından ABD' de 1.196 denetim ortağının Linkedin profillerini incelenerek yapılan çalışmada kadın denetçilerin oranı \%12,6 olarak belirlenmiştir. Bu çalışmada kadın denetim ortaklarının dört büyük firmada çalışma olasılığının dört büyük olmayan şirketlere göre daha yüksek olduğu da açıklanmıştır. Amerika Birleşik Devletleri'nde daha önce 2010 yılında yapılmış farklı bir araştırmada 4 büyük denetim firmalarından Deloitte ve KPMG'de, kadın denetçilerin ortaklık oranın \%18,8, PricewaterhouseCoopers'de ise \%16,9 olarak tespit edilmiştir (Jeny ve Vasut, 2017:2). Literatürdeki çalışmalar denetim şirketlerinde erkeklere oranla kadın denetçilerin genel olarak varlıklarının düşük düzeyde kaldığını ve kadın denetçilerin yönetim seviyelerinde yeterince görev alamadıklarını ortaya koymaktadır. 


\section{3. ÇALIŞMA METODOLOJISİ VE BULGULAR}

Çalışmanın bu kısmında araştırma konusunun amacı, kapsamı, yöntemi ve bulguları ele alınmıştır.

\section{1. Çalışmanın Amacı}

Bu çalışmada temel amaç Türkiye'de bağımsız denetim sektöründe faaliyette bulunan denetim şirketlerinde kadın denetçilerin hangi unvanlarla ne düzeyde yönetime katılabildiklerinin ortaya konulmasıdır. $\mathrm{Bu}$ amaç doğrultusunda dört büyük denetim firmasının yerel ortakları ve uluslararası denetim ağlarının kolu olarak Türkiye'de faaliyette bulunan 8 bağımsız denetim şirketine yönelik bir araştırma gerçekleştirilmiştir.

\section{2. Çalışmanın Kapsamı ve Yöntemi}

Araştırmada çalışmanın amacı doğrultusunda Türkiye' de bağımsız denetim sektöründe faaliyette bulunan denetim şirketleri üzerine bir inceleme yapılmıştır. Araştırmada bağımsız denetim şirketleri seçilirken denetim gelirleri toplamı ve denetlenen KAYİK sayıları göz önüne alınmıştır. Hoitash, Markelevich ve Charles, (2007:762), Erdoğan ve Kutay (2016:109) ve Coşkun (2020:150) tarafindan yapılmış çalışmalarda denetim gelirleri denetim yapan firmanın bir kalite göstergesi olarak değerlendirilmekte ve yüksek denetim geliri elde eden denetim firmalarının daha kaliteli hizmet verebildiği öne sürülmektedir. Bununla birlikte denetim firmalarının denetledikleri KAYİK sayılarının fazla olması denetim firmasının kalitesinin ve bir büyüklük ölçüsünün unsuru olarak değerlendirilmektedir (DeFond ve Zhang, 2014:289, Erdoğan ve Kutay, 2016:108). Bu araştırmada da bağımsız denetim şirketleri seçilirken denetim kalitesi akademik yazınında kullanılan denetim gelirleri toplamı ve denetlenen KAYİK sayıları göz önüne alınmıştır. Ayrıca araştırma kapsamında verileri incelenen denetim firmaları Türkiye'deki bağımsız denetim sektöründe en fazla çalışan sayısına sahip şirketlerdir. Bu durumda çalışmada verileri kullanılan aşağıda isimleri belirtilen şirketlerin seçilmesinde etkili olmuştur. Araştırmada dört büyük olarak kabul edilen Deloitte, Ernst \& Young, KPMG, PWC denetim şirketleri ile Bakertilly Güreli, BDO Denet, Grant Thornton Eren, Mazars Denge denetim firmalarının 2015-2019 yılları arasındaki verileri çalışmanın amacı doğrultusunda incelenmiştir. Araştırmada bağımsız denetim şirketlerinde kadın denetçilerin yönetime katılma durumlarının belirlenebilmesi için denetim firmalarının yayınladıkları şeffaflık raporları kullanılmıştır. Şeffaflık raporları bağımsız denetim firmalarının internet sitelerinden temin edilmiştir. Şeffaflık raporlarında kadın denetçilerin yönetime katılma durumlarının tespiti için ortak denetçi, ortak kadın denetçi hisse oranı, yönetim kurulu üyesi, yönetim kurulu başkanı, kilit yönetici, sorumlu ortak baş denetçi, sorumlu denetçi gibi unvanları incelenmiştir. Bu kapsamda çalışmada 8 bağımsız denetim firmasının 2015-2019 yıllarına ait toplam 40 adet şeffaflık raporu yukarıda açıklanan unvan başlıklarına göre görev alan kadın denetçilerin isimleri dikkate alınarak taranmıştır. Yapılan inceleme sonucunda elde edilen kadın denetçilerin unvanlarına göre sayıları denetim firması bazında oluşturulan kontrol listelerine aktarılmıştır. Kontrol listelerindeki veriler SPSS IBM programı kullanılarak betimleyici istatiksel yöntem uygulanmak suretiyle frekans ve yüzde değerleri üzerinden analiz edilmiştir. Betimleyici (descriptive analysis) analizde temel yaklaşım kantitatif şeklinde bir değişkene ait verilerin tablolar ve grafikler kullanılarak ortaya koyulmasıdır. Genelde yapılan çalışmalarda bir örneklem içerisinde yer alan verilerin içerisinde demografik özelliklerin tespit edilmesinde kullanılabilmektedir (Gürbüz ve Şahin, 
2016:220). Konu çerçevesinde literatürde Ittonen ve Peni (2012), Bozcuk (2018), Hairston vd. (2019), Downar vd. (2020) tarafından yapılan farklı çalışmalarda çeşitli yıllardaki verilerde ayrı yöntemler kullanmış olsalar da demografik özelliklere göre verileri frekans ve yüzde değerleri üzerinden değerlendirdikleri görülmüştür.

\section{3. Çalışmanın Bulguları}

Çalışmanın bu bölümünde araştırmanın amacı ve kapsamı bölümünde açıklanan bilgiler doğrultusunda ulaşılan sonuçlar ele alınmıştır. Bulgularda öncelikle denetim firması bazında kadın denetçilerin unvanlara göre görev alma düzeyleri incelenmiştir. Ardından erkek ve kadın denetçilerin yönetime katılma durumları için unvanlara göre karşılaştırılması yapılmıştır. Son olarak Türkiye'de kadın denetçilerin incelenen yıllar itibari ile yönetimdeki düzeylerinin ortaya konulmasına çalışılmıştır.

Tablo 1. Bağımsız Denetim Firmalarına Göre Ortak Kadın Denetçi Sayısı

\begin{tabular}{|c|c|c|c|c|c|c|c|c|}
\hline Yillar & $\begin{array}{c}\text { Bakertilly } \\
\text { Güreli }\end{array}$ & $\begin{array}{c}\text { BDO } \\
\text { Denet }\end{array}$ & Deloitte & EY & $\begin{array}{c}\text { Grant } \\
\text { Thornton } \\
\text { Eren }\end{array}$ & KPMG & $\begin{array}{c}\text { Mazars } \\
\text { Denge }\end{array}$ & PWC \\
\hline 2015 & 3 & 0 & 7 & 9 & 0 & 3 & 0 & 9 \\
\hline 2016 & 3 & 0 & 7 & 8 & 0 & 3 & 2 & 8 \\
\hline 2017 & 3 & 0 & 0 & 8 & 0 & 8 & 2 & 8 \\
\hline 2018 & 3 & 0 & 6 & 7 & 0 & 11 & 2 & 8 \\
\hline 2019 & 3 & 0 & 5 & 9 & 0 & 11 & 1 & 7 \\
\hline Toplam & 15 & 0 & 25 & 41 & 0 & 36 & 7 & 40 \\
\hline
\end{tabular}

Çalışma kapsamında incelenen 2015-2019 yılları arasında kadın denetçilerin ortak olarak en çok yer aldıkları firmalar dört büyük olarak kabul edilen denetim şirketleridir. Yukarıda Tablo 1'de görüleceği üzere 2015-2019 yılları arasında en çok ortak kadın denetçi sayısı dört büyüklerden olan EY bağımsız denetim firmasındadır. İkinci en çok kadın ortak denetçi sayısı ise PWC denetim firmasındadır. Kadın ortak denetçilerin sayı olarak fazla olduğu üçüncü sırada KPGM, dördüncü sırada ise Deloitte denetim firması bulunmaktadır. Dört büyük denetim firması dışında kabul edilen uluslararası denetim ağının bir parçası olan ve dünya genelinde yüksek bir oranda müşterisi sayısı bulunan Bakertilly ve Mazars denetim firmalarının Türkiye kolunda yer alan şirketlerde ise incelenen yıllarda düşük düzeyde kadın ortak denetçiler bulunduğu tespit edilmiştir. Diğer denetim firmalarının Türkiye ortaklarında kadın ortak denetçilerin incelenen yıllarda yer almadıkları görülmüştür.

Tablo 2. Bağımsız Denetim Firmalarına Göre Yönetimdeki Ortak Kadın Denetçi Hisse Oranı

\begin{tabular}{|c|c|c|c|c|c|c|c|c|}
\hline Yillar & $\begin{array}{c}\text { Bakertilly } \\
\text { Güreli }\end{array}$ & $\begin{array}{c}\text { BDO } \\
\text { Denet }\end{array}$ & Deloitte & EY & $\begin{array}{c}\text { Grant } \\
\text { Thornton } \\
\text { Eren }\end{array}$ & KPMG & $\begin{array}{c}\text { Mazars } \\
\text { Denge }\end{array}$ & PWC \\
\hline 2015 & 0,01 & 0 & 9,7 & 50 & 0 & 12 & 0 & 28,56 \\
\hline 2016 & 0,01 & 0 & 9,7 & 55,77 & 0 & 12 & 25,26 & 28,56 \\
\hline 2017 & 0,01 & 0 & 0 & 55,72 & 0 & 25 & 12,5 & 28,56 \\
\hline
\end{tabular}




\begin{tabular}{|c|c|c|c|c|c|c|c|c|}
2018 & 0,01 & 0 & 23,76 & 49,98 & 0 & 25 & 0,2 & 28,56 \\
\hline 2019 & 0,01 & 0 & 23,76 & 50 & 0 & 26 & 0,2 & 21,42 \\
\hline Toplam & 0,05 & 0 & 66,92 & 261,47 & 0 & 100 & 38,16 & 135,66 \\
\hline
\end{tabular}

Bağımsız denetim firmalarında ortak olarak yer alan kadın denetçilerin hisse bazında temsilleri için Tablo 2'deki veriler incelendiğinde; en çok ortaklık payı dört büyük denetim firmaları içerisinde yer alan denetim şirketlerinde olduğu görülmektedir. Ortaklık düzeyi olarak kadın denetçilerin en fazla olduğu denetim firması EY denetim firmasıdır. İkinci olarak kadın denetçi ortaklık düzeyi yüksek olan denetim firması PWC, üçüncü sırada KPGM, dördüncü sırada ise Deloitte firması gelmektedir. Dört büyük denetim firması dışında yer alan denetim firması olan Mazars Denge Türkiye ortaklığında 2016 ve 2017 yılında kadın ortak denetçilerin hisseleri bulunmaktadır. Bakertilly Güreli denetim firmasında ise kadın ortak denetçi sayısı incelenen her yılda 3 kişi olmasına karşılık hisse oranı çok düşük seviyededir. Dört büyük denetim firmaları dışında yer alan diğer denetim firmalarında 2015-2019 yılları arasında kadın ortak denetçi olmadığı için hisse olarak bir ortaklık payları bulunmadığı tespit edilmiştir.

Tablo 3. Bağımsız Denetim Firmalarına Göre Yönetim Kurulundaki Kadın Denetçi Sayısı

\begin{tabular}{|c|c|c|c|c|c|c|c|c|}
\hline Yıllar & $\begin{array}{c}\text { Bakertilly } \\
\text { Güreli }\end{array}$ & $\begin{array}{c}\text { BDO } \\
\text { Denet }\end{array}$ & Deloitte & EY & $\begin{array}{c}\text { Grant } \\
\text { Thornton } \\
\text { Eren }\end{array}$ & KPMG & $\begin{array}{c}\text { Mazars } \\
\text { Denge }\end{array}$ & PWC \\
\hline 2015 & 0 & 0 & 1 & 3 & 0 & 1 & 0 & 4 \\
\hline 2016 & 0 & 0 & 1 & 3 & 0 & 1 & 2 & 4 \\
\hline 2017 & 0 & 0 & 0 & 3 & 0 & 1 & 1 & 4 \\
\hline 2018 & 0 & 0 & 1 & 3 & 0 & 1 & 0 & 5 \\
\hline 2019 & 0 & 0 & 1 & 3 & 0 & 1 & 0 & 4 \\
\hline Toplam & 0 & 0 & 4 & 15 & 0 & 5 & 3 & 21 \\
\hline
\end{tabular}

Bağımsız denetim firmalarının yönetim kurullarında yer alan kadın denetçilerin düzeyi için yukarıdaki Tablo 3 incelendiğinde; yönetim kurulunda en çok kadın denetçi bulunan bağımsız denetim firması dört büyükler içerisindeki PWC denetim firmasıdır. Aynı kapsamdaki değerlendirmede ikinci sırada gelen EY denetim firmasıdır. EY denetim firmasının kadın denetçi ortak sayısı ve hisse oranı PWC denetim firmasından incelenen yıllar itibari ile fazla olmasına karşılık yönetim kurulundaki kadın denetçi sayısı PWC denetim firmasından geride kalmıştır. Diğer yandan kadın denetçilerin yönetim kurullarında en çok yer alan üçüncü sıradaki denetim firması ise KPGM, dördüncü sırada ise Deloitte firması gelmektedir. Dört büyük denetim firması dışında kalan denetim firmalarının Türkiye ortaklıkları içerisinde kadın denetçilere yönetim kurulunda yer veren tek denetim şirketi Mazars Denge denetim firması olduğu tespit edilmiştir. 
Tablo 4. Bağımsız Denetim Firmalarına Göre Yönetim Kurulu Başkanlığındaki Kadın Denetçi Say1s1

\begin{tabular}{|c|c|c|c|c|c|c|c|c|}
\hline Yıllar & $\begin{array}{c}\text { Bakertilly } \\
\text { Güreli }\end{array}$ & $\begin{array}{c}\text { BDO } \\
\text { Denet }\end{array}$ & Deloitte & EY & $\begin{array}{c}\text { Grant } \\
\text { Thornton } \\
\text { Eren }\end{array}$ & KPMG & $\begin{array}{c}\text { Mazars } \\
\text { Denge }\end{array}$ & PWC \\
\hline 2015 & 0 & 0 & 0 & 1 & 0 & 0 & 0 & 0 \\
\hline 2016 & 0 & 0 & 0 & 1 & 0 & 0 & 0 & 0 \\
\hline 2017 & 0 & 0 & 0 & 1 & 0 & 0 & 0 & 0 \\
\hline 2018 & 0 & 0 & 0 & 1 & 0 & 0 & 0 & 0 \\
\hline 2019 & 0 & 0 & 0 & 1 & 0 & 0 & 0 & 0 \\
\hline Toplam & 0 & 0 & 0 & 5 & 0 & 0 & 0 & 0 \\
\hline
\end{tabular}

Kadın denetçilerin denetim firmalarında yönetim kurulu başkanı olarak görev alma durumları için yukarıda Tablo 4 incelendiğinde; sadece dört büyük denetim firması içerisinde yer alan EY denetim firmasında yönetim kurulu başkanlığ görevini kadın bir denetçinin üstlendiği görülmektedir. Diğer dört büyük ve dört büyük dışında kalan denetim firmalarında ise yönetim kurulu başkanlığı görevi erkek denetçiler tarafından yerine getirildiği tespit edilmiştir.

Tablo 5. Bağımsız Denetim Firmalarına Göre Yönetimdeki Kadın Kilit Yönetici Denetçi Sayı1

\begin{tabular}{|c|c|c|c|c|c|c|c|c|}
\hline Yillar & $\begin{array}{c}\text { Bakertilly } \\
\text { Güreli }\end{array}$ & $\begin{array}{c}\text { BDO } \\
\text { Denet }\end{array}$ & Deloitte & EY & $\begin{array}{c}\text { Grant } \\
\text { Thornton } \\
\text { Eren }\end{array}$ & KPMG & $\begin{array}{c}\text { Mazars } \\
\text { Denge }\end{array}$ & PWC \\
\hline 2015 & 1 & 0 & 6 & 3 & 0 & 1 & 0 & 4 \\
\hline 2016 & 1 & 0 & 6 & 3 & 0 & 1 & 2 & 4 \\
\hline 2017 & 3 & 0 & 0 & 3 & 0 & 1 & 1 & 4 \\
\hline 2018 & 3 & 0 & 5 & 3 & 0 & 1 & 0 & 5 \\
\hline 2019 & 3 & 0 & 5 & 3 & 0 & 1 & 0 & 4 \\
\hline Toplam & 11 & 0 & 22 & 15 & 0 & 5 & 3 & 21 \\
\hline
\end{tabular}

Araştırma kapsamında incelenen yıllarda bağımsız denetim firmalarında kadın denetçilerin kilit yönetici olarak daha çok dört büyük denetim firmalarında görev aldıkları yukarıda Tablo 5 verilerinde görülmektedir. En çok kadın denetçinin kilit yönetici olarak görev aldığı bağımsız denetim şirketinin Deloitte denetim firması olduğu, ardından ikinci sırada PWC, üçüncü sırada ise EY denetim firmalarının geldiği görülmektedir. Dört büyükler içerisinde KPMG denetim firmasında ise kadın denetçilerin kilit yönetici olarak en az oranda 
görev aldığı görülmektedir. Dört büyükler içerisinde yer almayan uluslararası ağ içerisinde bulunan Bakertilly denetim firmasının Türkiye ortağı olan Güreli denetim firmasında kadın denetçilerin kilit yönetici olarak görev alma seviyesi 8 denetim firması içerisinde dördüncü sıradadır. Bununla birlikte dört büyükler içerisinde yer almayan Mazars denetim firmasının Türkiye kolunda kadın denetçilere kilit yönetici olarak 2016 ve 2017 yıllarında yer verildiği görülmektedir.

Tablo 6. Bağımsız Denetim Firmalarına Göre Kadın Sorumlu Ortak Baş Denetçi Sayısı

\begin{tabular}{|c|c|c|c|c|c|c|c|c|}
\hline Yillar & $\begin{array}{c}\text { Bakertilly } \\
\text { Güreli }\end{array}$ & $\begin{array}{c}\text { BDO } \\
\text { Denet }\end{array}$ & Deloitte & EY & $\begin{array}{c}\text { Grant } \\
\text { Thornton } \\
\text { Eren }\end{array}$ & KPMG & $\begin{array}{c}\text { Mazars } \\
\text { Denge }\end{array}$ & PWC \\
\hline 2015 & Bilgi Yok & 0 & Bilgi Yok & 1 & 0 & Bilgi Yok & Bilgi Yok & Bilgi Yok \\
\hline 2016 & Bilgi Yok & 0 & Bilgi Yok & 1 & 0 & Bilgi Yok & Bilgi Yok & Bilgi Yok \\
\hline 2017 & Bilgi Yok & 0 & Veri Yok & 1 & 0 & Bilgi Yok & Bilgi Yok & Bilgi Yok \\
\hline 2018 & Bilgi Yok & 0 & Bilgi Yok & 1 & 0 & Bilgi Yok & Bilgi Yok & Bilgi Yok \\
\hline 2019 & Bilgi Yok & 0 & Bilgi Yok & 1 & 0 & Bilgi Yok & Bilgi Yok & Bilgi Yok \\
\hline
\end{tabular}

Çalışma verilerine göre 2015-2019 yılları arasında kadın denetçilerin sorumlu ortak baş denetçi sayılarına ilişkin bilgilere Tablo 6'da görüleceği üzere ulaşılamamıştır. Bununla birlikte denetim firmalarının şeffaflık raporları incelemesi sonucunda denetçi isimlerinin önünde sorumlu ortak baş denetçi unvanı bulunan kadın denetçi sadece dört büyükler içerisinde yer alan EY denetim firmasında olduğu tespit edilmiştir. Diğer denetim firmalarının şeffaflık raporlarından bu kapsamdaki veriler elde edilememiştir. $\mathrm{Bu}$ durum denetim firmalarının açıklamış oldukları bilgilerde bir eksiklik olmadığı düşünüldüğünde sadece kadın sorumlu ortak baş denetçi unvanına sahip tek bir bağımsız denetim firması olduğu sonucunu ortaya koymaktadır.

Tablo 7. Bağımsız Denetim Firmalarına Göre Sorumlu Kadın Denetçi Sayısı

\begin{tabular}{|c|c|c|c|c|c|c|c|c|}
\hline Yıllar & $\begin{array}{c}\text { Bakertilly } \\
\text { Güreli }\end{array}$ & $\begin{array}{c}\text { BDO } \\
\text { Denet }\end{array}$ & Deloitte & EY & $\begin{array}{c}\text { Grant } \\
\text { Thornton } \\
\text { Eren }\end{array}$ & KPMG & $\begin{array}{c}\text { Mazars } \\
\text { Denge }\end{array}$ & PWC \\
\hline 2015 & 1 & Bilgi Yok & 6 & 9 & 0 & 3 & 0 & 7 \\
\hline 2016 & 1 & Bilgi Yok & 6 & 8 & 0 & 3 & 2 & 7 \\
\hline 2017 & 3 & Bilgi Yok & 0 & 8 & 0 & 9 & 0 & 6 \\
\hline 2018 & 3 & Bilgi Yok & 5 & 7 & 0 & 9 & 1 & 5 \\
\hline 2019 & 3 & Bilgi Yok & 5 & 9 & 0 & 10 & 0 & 5 \\
\hline Toplam & 11 & Bilgi Yok & 22 & 41 & 0 & 34 & 3 & 30 \\
\hline
\end{tabular}


Araştırma kapsamında incelenen y1llarda Tablo 7'de görüleceği üzere kadın denetçilerin sorumlu denetçi unvanı ile daha çok dört büyük denetim firmalarında görev alabildiği görülmektedir. Dört büyükler içerisinde kadın denetçilerin sorumlu denetçi unvanı ile en çok EY denetim firmasında görev aldıkları, buna karşın en az oranda ise Deloitte denetim firmasında yer aldıkları gözlemlenmiştir. Dört büyükler dışında kalan uluslararası denetim ağının Türkiye kolunda yer alan denetim firmaları içerisinde sorumlu kadın denetçi sayısı en fazla Bakertilly Güreli denetim firmasındadır. Aynı kapsamda ikinci sırada ise Mazars Denge bağımsız denetim firması gelmektedir. Diğer denetim firmalarında sorumlu kadın denetçi varlığı incelenen yıllarda tespit edilememiştir.

Tablo 8. Araştırma Kriterlerine Göre 2015-2019 Yılları Arasında Denetim Firmaları Bazında Kadın Denetçilerin Yönetime Katılma Toplam Sayıları

\begin{tabular}{|c|c|c|c|c|c|c|c|c|}
\hline Unvanlar & $\begin{array}{c}\text { Bakertilly } \\
\text { Güreli }\end{array}$ & $\begin{array}{c}\text { BDO } \\
\text { Denet }\end{array}$ & Deloitte & EY & $\begin{array}{c}\text { Grant } \\
\text { Thornton } \\
\text { Eren }\end{array}$ & KPMG & $\begin{array}{c}\text { Mazars } \\
\text { Denge }\end{array}$ & PWC \\
\hline Ortak Denetçi & 15 & 0 & 25 & 41 & 0 & 36 & 7 & 40 \\
\hline Yönetim Kurulu Üyesi & 0 & 0 & 4 & 15 & 0 & 5 & 3 & 21 \\
\hline $\begin{array}{c}\text { Yönetim Kurulu } \\
\text { Başkanı }\end{array}$ & 0 & 0 & 0 & 5 & 0 & 0 & 0 & 0 \\
\hline $\begin{array}{c}\text { Kilit Yönetici } \\
\text { Sorumlu Ortak Baş }\end{array}$ & 0 & 0 & 0 & 1 & 0 & 0 & 0 & 0 \\
\hline Denetçi & 11 & 0 & 22 & 41 & 0 & 34 & 3 & 30 \\
\hline Sorumlu Denetçi & & 0 & 22 & 15 & 0 & 5 & 3 & 21 \\
\hline
\end{tabular}

Çalışma kapsamında bulunan bağımsız denetim firmalarının kadın denetçilerin yönetimde görev alma durumları için yukarıdaki Tablo 8 verileri değerlendirildiğinde; ortak denetçi unvanı ile en çok kadın denetçiler sırasıyla EY, PWC, KPMG, Deloitte ve Bakertlilly Güreli bağımsız denetim firmalarında yer almışlardır. Kadın denetçilerin yönetim kurulu üyesi olarak yer alabildikleri denetim firmaları birinci sırada PWC, ikinci sırada ise EY bağımsız denetim şirketidir. BDO Denet ve Grant Thornton Eren bağımsız denetim firmalarında incelenen beş yıllık veriler dikkate alındığında yönetim kurullarında kadın denetçi bulunmamaktadır. Yönetim kurulu başkanlığı görevinin 5 yıl boyunca kadın denetçi tarafından yürütülen tek bağımsız denetim şirketi EY firması olduğu görülmektedir. Kilit yönetici olarak görev alma durumları incelendiğinde ise, kadın denetçilere en çok yer veren denetim firmaları sırasıyla Deloitte, PWC, EY, Bakertilly Güreli şirketleri olmuştur. BDO Denet ve Grant Thornton Eren bağımsız denetim firmalarında kilit yöneticiler içerisinde kadın denetçiler görev almamıştır. Sorumlu ortak baş denetçi olarak kadın denetçisi bulunan tek şirket EY bağımsız denetim firmasıdır. Kadın denetçilere en çok sorumlu denetçi olarak görev verilen bağımsız denetim firmaları sırasıyla; EY, KPMG, PWC, Deloitte, Bakertilly Güreli denetim şirketleridir. 


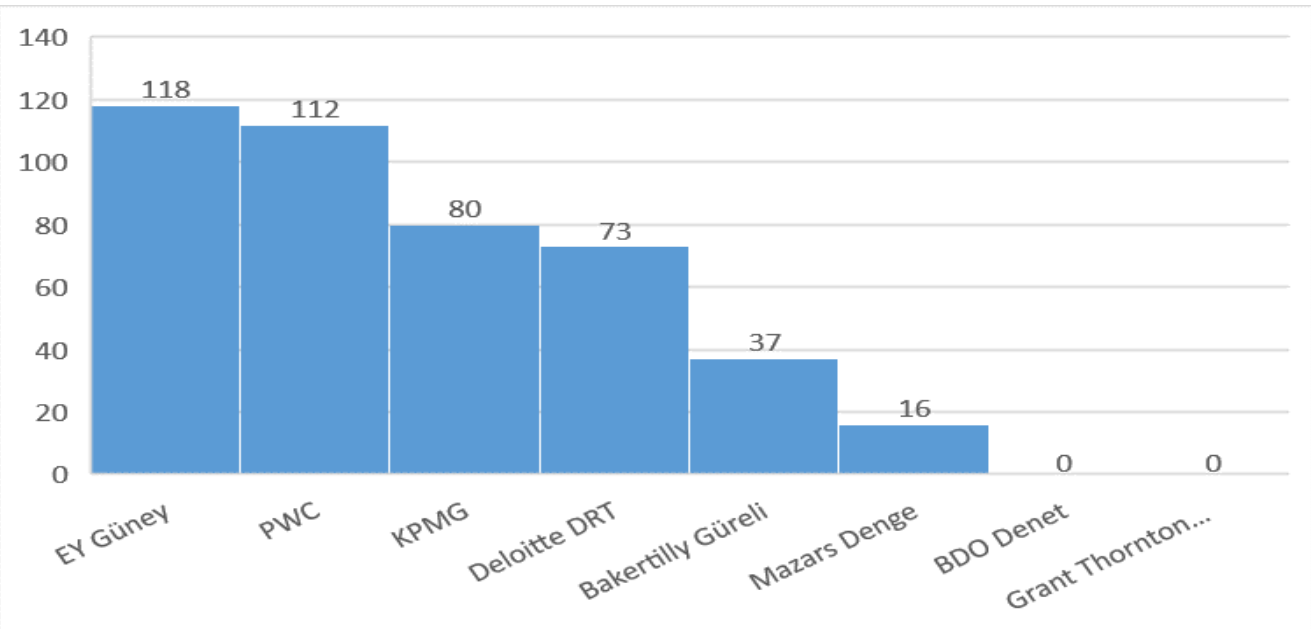

Grafik 1. Tüm yıllardaki Verilere Göre Bağımsız Denetim Firmaları Bazında Kadın Denetçilerin Durumları

Grafik 1 verileri incelendiğinde araştırma kapsamındaki tüm unvanlara göre 20152019 yılları arasında kadın denetçilerin en çok yer alabildiği bağımsız denetim firmaları dört büyükler olarak kabul edilen denetim şirketleri olduğu görülmektedir. Dört büyük denetim şirketleri içerisinde kadın denetçilerin en çok yer aldığı denetim şirketi ise EY denetim firmasıdır. Bu kapsamda dört büyükler içerisinde son sırada Deloitte denetim firması gelmektedir. Dört büyükler dışında araştırma kapsamında belirlenen unvanlara göre ilk sırada kadın denetçilerin yer aldıkları bağımsız denetim firması Bakertilly Güreli denetim şirketidir. İkinci surada ise Mazars Denge denetim firması bulunmaktadır. BDO Denet ve Grant Thornton Eren denetim firmalarında araştırma kapsamında belirlenen unvanlara kadın denetçi varlığ 1 tespit edilememiştir.

Tablo 9. Tüm Denetim Firmalarındaki Araştırma Kapsamındaki Verilere Göre Kadın ve Erkek Denetçilerin Yönetimdeki Sayılarının Karşılaştırılması

\begin{tabular}{|l|c|c|c|c|c|c|c|c|c|c|}
\hline \multirow{2}{*}{ Unvanlar } & \multicolumn{4}{|c|}{ KADIN } & \multicolumn{4}{c|}{ ERKEK } & \multicolumn{3}{c|}{ FARK } \\
\cline { 2 - 11 } & Minimum & Maximum & $\begin{array}{c}\text { Sum } \\
\text { (toplam) }\end{array}$ & $\begin{array}{c}\text { Mean } \\
\text { (ortalama) }\end{array}$ & Minimum & Maximum & $\begin{array}{c}\text { Sum } \\
\text { (toplam) }\end{array}$ & $\begin{array}{c}\text { Mean } \\
\text { (ortalama) }\end{array}$ & Kadın & Erkek \\
\hline $\begin{array}{l}\text { Ortak } \\
\text { Denetçi }\end{array}$ & 29 & 37 & 164 & 32,8 & 71 & 92 & 435 & 87 & 27,38 & 72,62 \\
\hline $\begin{array}{l}\text { Y. Kurulu } \\
\text { Üyesi }\end{array}$ & 9 & 11 & 48 & 9,6 & 32 & 38 & 179 & 35,8 & 21,15 & 78,85 \\
\hline $\begin{array}{l}\text { Y.Kurulu } \\
\text { Başkanı }\end{array}$ & 1 & 1 & 5 & 1 & 6 & 7 & 34 & 6,8 & 12,82 & 87,18 \\
\hline $\begin{array}{l}\text { Kilit } \\
\text { Yönetici } \\
\text { Sayıs1 }\end{array}$ & 12 & 17 & 77 & 15,4 & 38 & 56 & 243 & 48,6 & 24,06 & 75,94 \\
\hline $\begin{array}{l}\text { Sorumlu } \\
\text { Ortak Baş } \\
\text { Denetçi }\end{array}$ & 1 & 1 & 5 & 1 & 7 & 13 & 58 & 11,6 & 7,94 & 92,06 \\
\hline $\begin{array}{l}\text { Sorumlu } \\
\text { Denetçi }\end{array}$ & 26 & 32 & 141 & 28,2 & 50 & 68 & 295 & 59 & 32,34 & 67,66 \\
\hline
\end{tabular}

Çalışma kapsamında 2015-2016 yıllarındaki yukarıdaki Tablo 9'daki veriler değerlendirildiğine; kadın denetçilerin genel olarak erkek denetçilere oranla araştırma kapsamındaki unvanlara göre yönetime katılma düzeylerinin düşük oranda olduğu 
görülmektedir. Kadın denetçilerin unvanlara göre en çok ortak denetçi, sonrasında ise sorumlu denetçi ve ardından kilit yönetici ile yönetim kurulu üyesi pozisyonunda görev alabildikleri görülmektedir. Bu sonuçlar kadın denetçilerin sorumlu ortak baş denetçi, yönetim kurulu üyesi, yönetim kurulu başkanı görevlerinde temsil oranlarının erkek denetçilere oranla oldukça düşük seviyede olduğunu göstermektedir. Çalışma verileri Türkiye'de faaliyet gösteren dört büyük denetim firmalarının yerel ortaklıkları dahil olmak üzere diğer uluslararası denetim ağlarının bir parçası olarak faaliyet bulunan denetim firmalarında kadın denetçilerin yönetime katılma oranlarının düşük seviyede olduğunu ortaya koymaktadır. Literatürdeki farklı ülkelerde yapılan diğer çalışmalar ile araştırma sonuçları karşılaştırıldığında Türkiye'deki kadın denetçilerin yönetime katılma durumları ile derin farklılık olmadı̆̆ı ortaya çıkmaktadır. Örneğin Downar vd., (2020) tarafından Almanya'da 2014-2018 yılları arasında dört büyük denetim firması üzerine yapılan çalışmada 397 denetçi içerisinde kadın denetçilerin ortalama oranı \%21'dir. Kıdemli ortak 63 denetçi içerisinde kadın denetçilerinin ortalama oranı ise \%11 olarak tespit edilmiştir. Hairston vd., (2019), tarafından yakın zamanda ABD'de 1.196 denetim ortağının Linkedin profillerini incelenerek yapılan çalışmada da tüm unvanlara göre kadın denetçilerin oranı \%12,6 olarak tespit edilmiştir.

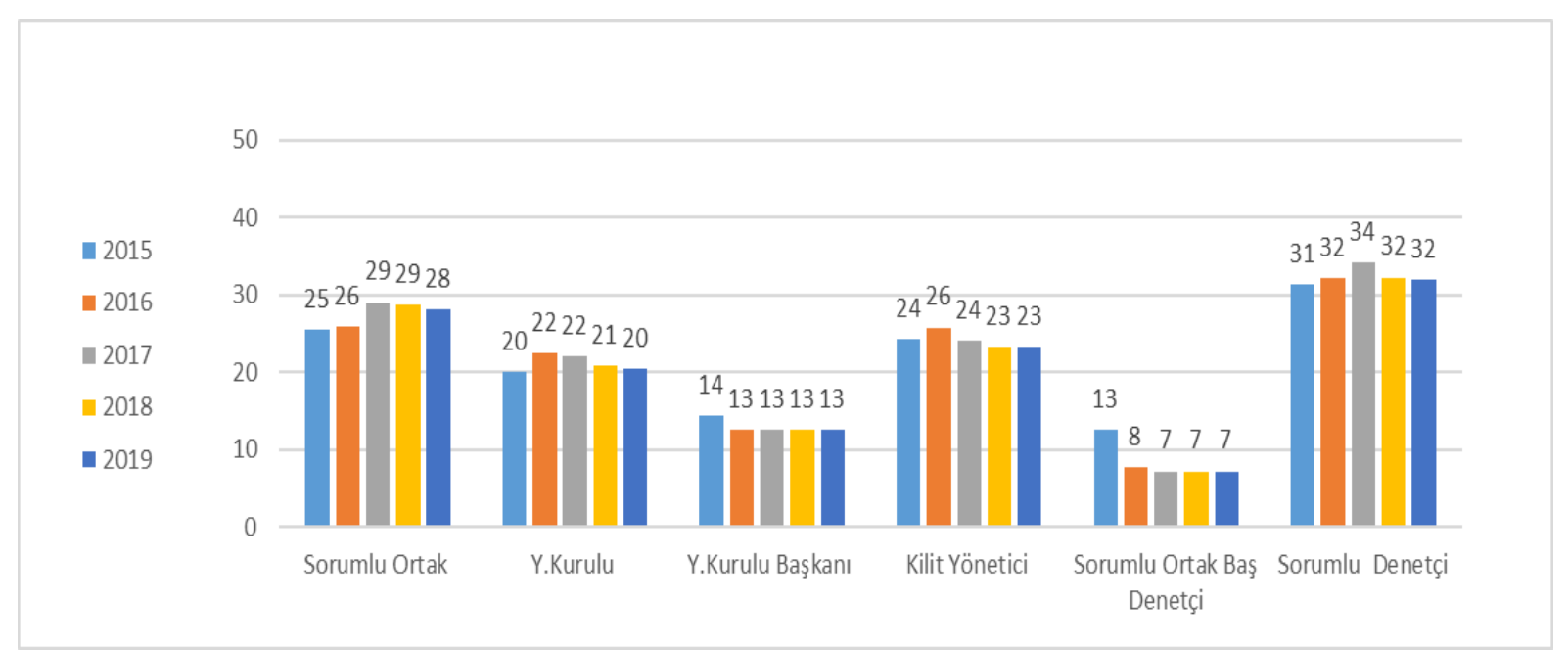

Grafik 2. İncelenen Yıllara Göre Tüm Denetim Şirketleri Bazında Kadın Denetçilerin Unvanlarına Göre Dağılımları

Yukarıdaki Grafik 2 verileri kadın denetçilerin unvan dağılımlarının kendi içerisinde incelenen yıllar itibari ile yönetime katılma durumlarında çok büyük bir değişiklik olmadığını göstermektedir. Bununla birlikte sorumlu ortak baş denetçi oranı 2015 y1lında diğer yıllara göre daha yüksek bir seviyede iken daha sonra aşağı yönlü bir eğilim izlemiştir. Genel olarak 5 yıllık çalışma verileri bağımsız denetim firmalarında kadın denetçilerin araştırma kapsamında belirlenen unvanlara göre yönetime katılma oranlarının sabit kaldığını ve yıllar arasında yüksek bir artış veya azalış eğiliminin olmadığını ortaya koymaktadır.

\section{SONUÇ}

Çalışma kapsamında Türkiye'de bağımsız denetim şirketlerinde kadın denetçilerin ortak denetçi ve hisse oran1, yönetim kurulu üyesi, yönetim kurulu başkan1, kilit yönetici, sorumlu ortak baş denetçi ve sorumlu denetçi gibi unvanlarla yönetime ne derecede katılabildikleri araştırılmıştır. $\mathrm{Bu}$ çerçevede Türkiye'de bağımsız denetim sektöründe faaliyette bulunan aralarında dört büyük denetim şirketlerinin bulunduğu 8 büyük denetim 
firmasının şeffaflık raporları üzerine bir inceleme yapılmıştır. Bu kapsamda çalışmada 8 bağımsız denetim firmasının 2015-2019 yıllarına ait şeffaflık raporları incelenmiştir.

Çalışma sonuçları; kadın denetçilerin unvanlara göre en çok ortak denetçi, sonrasında ise sorumlu denetçi ve ardından kilit yönetici ile yönetim kurulu üyesi pozisyonunda görev alabildiklerini göstermiştir. Çalışma verileri kadın denetçilerin tek bir bağımsız denetim şirketinde yönetim kurulu başkanlığı görevini yerine getirdiğini ve kadın denetçilerin daha çok dört büyük denetim firmalarında temsil hakkı elde edebildiğini ortaya koymuştur. Dört büyükler içerisinde araştırılan tüm unvanlara göre kadın denetçilerin en çok EY bağımsız denetim şirketinde temsil edildiği görülmüştür. Araştırma sonuçları genel olarak incelenen yıllarda bağımsız denetim şirketlerinde erkek denetçilerin kadın denetçilere oranla yönetimde daha çok görev aldıklarını ve kadın denetçilerin yönetimde varlıklarının daha düşük düzeyde olduğunu göstermiştir. Bununla birlikte son zamanda literatürde yapılan çalışmalarda araştırma kapsamında incelenen dört büyük olarak kabul edilen bağımsız denetim şirketlerinin başka ülkelerdeki faaliyet gösteren kollarında da örneğin gelişmiş ülke kategorisinde olan Almanya ve ABD gibi devletlerde de kadın denetçilerin yönetime katılma oranlarının düşük olduğunu göstermektedir. Elbette ki daha kesin bir yargıya varabilmek için ülkeler arasında kadın çalışanların denetim firmalarındaki yönetimdeki dağılımlarının karşılaştırmalı olarak incelenmesi gerekmektedir. $\mathrm{Bu}$ yönüyle çalışma verileri daha geniş bir ölçüde değerlendirilerek ileride başka araştırmalarda ele alınabilir. Buna karşın mevcut literatürde ulaşılabilen araştırma sonuçları ile bu çalışmanın sonuçları kadın denetçilerin genel olarak bağımsız denetim firmalarında yönetime katılma durumlarının düşük düzeyde kaldığına işaret etmektedir.

\section{KAYNAKLAR}

Abdelfattah, Tarek - Elmahgoub, Mohamed - Elamer, Ahmed A. (2020), "Female Audit Partners And Extended Audit Reporting: UK Evidence”, Journal of business ethics, September, pp. 1-21.

Abed, Suzan- Al-badainah, Jomana (2013), “The Impact Of Auditor's Gender On Audit Fees: Case of Jordanian auditors”, International journal of business and management, 8, 4, pp. 127-133.

Arioglu, Emrah (2020), “The Affiliations And Characteristics Of Female Directors And Earnings Management: Evidence From Turkey”, Managerial Auditing Journal, 35,7, pp. 927-953.

Baskan, Tuba Derya (2018), "Firmaların Denetim Sonuçlarının Yönetim Kurulu Bileşenlerine Etkisi: Perakende Ve Çimento Sektöründe İnceleme”, İşletme Araştırmaları Dergisi, 10,1, ss. 198-211.

Bozcuk, Aslıhan E. (2018), “Türkiye'deki Bağımsız Denetim Kuruluşlarında Üst Düzeydeki Cinsiyet Çeşitliliği Ve Gelir Etkisi”, Uluslararası Sosyal Araştırmalar Dergisi, 11, 59, Ekim, ss. 882-890.

Breesch, Diane - Branson, Joel (2009), “The Effects Of Auditor Gender On Audit Quality”, IUP Journal Of Accounting Research \& Audit Practices, 0, 3-4, July-October pp. 77107. 
Burke, Jenna J. - Hoitash, Rani - Hoitash, Udi (2019), “Audit Partner İdentification And Characteristics: Evidence from US Form AP Filings”, Auditing: A Journal Of Practice \& Theory, 38(3), pp. 71-94.

Burke, Ronald J.- Vinnicombe, Susan (2008), Women on corporate Boards Of Directors, International Research And Practice, Edward elgar publishing limited, UK.

Coşkun, Sedat (2020), Sosyal Bilimler Çerçevesinde Güncel Alan Araştırmaları, Gazi Kitapevi, Ankara.

Dambrin, Claire- Lambert, Caroline (2008), "Mothering or Auditing? The Case Of Two Big Four in France”, Accounting, auditing \& accountability journal, 21, 4, January, pp. 474-506.

DeFond, Mark- Zhang, Jieying (2014), “A Review Of Archival Auditing Research”, Journal of Accounting And Economics, 58, 2-3, September, pp. 275-326.

DeFond, Mark L.- Francis, Jere R. (2005) “Audit Research After Sarbanes-Oxley”, Auditing: A Journal Of Practice \& Theory, 24, 1, pp. 5-30.

Downar, Benedikt - Ernstberger, Jürgen - Koch, Christopher (2020), "Who Makes Partner İn Big 4 Audit Firms?-Evidence From Germany”, Accounting, Organizations And Society, 101176, October, pp 1-19.

Erdoğan, Sedat- Kutay, Nilgün (2016), “Türkiye’de Bağımsız Denetim Şirketlerinin Karakteristiklerinin Bağımsız Denetim Gelirleri Üzerindeki Etkisi”, Uluslararası Yönetim İktisat Ve İşletme Dergisi, 12, 27, pp. 105-122.

Gürbüz, Sait- Şahin, Faruk (2016). Sosyal Bilimlerde Araştırma Yöntemleri, Seçkin Kitapevi, Ankara.

Hairston, Stephanie- Wu, Da - Yu, Ji (2019), “Analyzing The Linkedin Profiles Of Audit Partners: A Snapshot Of Firm Leadership,The CPA Journal, 89,3, March, pp. 54-57.

Hao, Jie - Pham, Viet - Guo, Meng (2021), "The Gender Effects of Audit Partners on Audit Outcomes: Evidence of Rule 3211 Adoption” Journal of Business Ethics, January, pp. $1-30$.

Hardies, Kris - Breesch, Diane- Branson, Joël (2015), “The Female Audit Fee Premium”, Auditing: A Journal of Practice \& Theory, 34(4), pp. 171-195.

Hardies, Kris - Vandenhaute, Laure Marie- Breesch, Diane (2018), “An Analysis of Auditors' Going-Concern Reporting Accuracy in Private Firms”, Accounting Horizons, 32(4), pp. 117-132.

Hatunoğlu, Zeynep- Nurettin, Koca (2020), "Denetim Firması Faaliyet Alanına Göre Bağımsız Denetçinin, Mesleki Bağlılık Ve Denetimde Kalite Alg1 Düzeyi”, Muhasebe ve Vergi Uygulamaları Dergisi, 13, 3, ss. 621-636. 
Hoitash, Roni - Ariel Markelevich - Charles, A. Barragato (2007), “Auditor Fees And Audit Quality, Managerial Auditing Journal, 22,8, September, pp. 761-786.

Ittonen, Kim - Peni, Emilia (2012), “Auditor's Gender And Audit Fees”, International Journal Of Auditing, 16,1,pp. 1-18.

Ittonen, Kim - Vähämaa, Emilia, Vähämaa, Sami (2013), "Female Auditors And Accruals Quality”, Accounting Horizons, 27(2), pp. 205-228.

Jeny, Anne -Vasut, Santacreu Estefania (2017), “New Avenues Of Research To Explain The Rarity Of Females At The Top Of The Accountancy Profession”, Palgrave communications, 3,1, March, pp. 1-10.

Krishnan, Gopal V. - Parsons, Linda M. (2008), “Getting to the Bottom Line: An Exploration Of Gender And Earnings Quality”, Journal of business ethics, 78,1, pp. 65-76.

Lee, Hye Seung (Grace) - Nagy, Albert L.- Zimmerman, Aleksandra B. (2019) “Audit Partner Assignments And Audit Quality in the United States”, The Accounting Review, 94(2), pp. 297-323.

Li, Liuchuang - Qi, Baolei- Tian, Gaoliang - Zhang, Guochang (2017), “The Contagion Effect Of Low-Quality Audits At The Level Of İndividual Auditors”, The Accounting Review, 92(1), pp.137-163.

Li, Xiaochong - Li, Yanxi (2020), "Female Independent Directors And Financial Irregularities In Chinese Listed Firms: From The Perspective Of Audit Committee Chairpersons”, Finance research letters, 32, 101320, January, pp. 1-15.

Özkiraz, Ahmet- Arslanel, M. Nazan (2011), “İkinci Meşrutiyet Döneminde Kadın Olmak”, Sosyal Ve Beşeri Bilimler Dergisi, 3,1, ss. 1-10.

Sarıçiçek, Reyhan- Aytekin, Mehmet (2020), “Türkiye’deki Bağımsız Denetçilerin Denetim Kalitesini Azaltan Davranışlarının Analizi”, Muhasebe Ve Finansman Dergisi, 87, Temmuz, ss. 89-106.

Watts, Ross L.- Zimmerman, Jerold L. (1981), “The Markets For Independence And Independent Auditors”, Working paper series no GBP 80-10, University Of Rochester, Rochester, Ny.

Yanık, Serap- Karataş, Muharrem (2017), "Denetim Raporlarının Geleceği: Yeni Düzenlemeler Ve Ülke Uygulamaları" Muhasebe Ve Finansman Dergisi, 73, Ocak, ss. $1-26$.

http://www3.weforum.org/docs/WEF_GGGR_2020.pdf, Erişim tarihi, 25.02.2021.

https://data.tuik.gov.tr/Bulten/Index?p=Istatistiklerle-Kadin-2019-33732， Erişim tarihi, 25.02.2021.

https://home.kpmg/tr/tr/home/gorusler/2017/05/kilidi-kirmak. Erişim tarihi, 25.02.2021. 
https://www.ilo.org/shinyapps/bulkexplorer0/?lang=en\&segment=indicator\&id=EAP2WAP_ S X_AGE_RT_A, Erişim tarihi, 15.02.2021. 